\title{
Títulos de anticuerpos antisulfátido en pacientes con cardiopatía chagásica crónica y con otras formas de cardiopatía
}

\author{
Rando García, ${ }^{1}$ José Luis Ávila, ${ }^{2}$ Miguel Rojas, ${ }^{2}$ \\ Alejandro Martínez, ${ }^{2}$ Wilfredo García ${ }^{1}$ y Patrick Bergel ${ }^{1}$
}

RESUMEN Aún no se ha podido encontrar un tratamiento específico para la enfermedad de Chagas, a pesar de su endemicidad en extensas zonas de la Región de las Américas. En estudios anteriores se ha propuesto la posibilidad de que el galactocerebrósido sulfatado presente en Trypanosoma cruzi podría actuar como inmunógeno para producir las concentraciones elevadas de anticuerpos antisulfátido que se han encontrado en pacientes con infección crónica por ese parásito. Ese fenómeno podría ser importante en la patogenia de los síntomas cardíacos o del sistema nervioso periférico que caracteriza a la enfermedad de Chagas, que es la primera causa de miocarditis en Centroamérica y América del Sur y la segunda causa de insuficiencia cardíaca en algunos países de esas subregiones. El presente estudio se realizó con objeto de determinar si había diferencia entre pacientes con la enfermedad de Chagas y otros pacientes sin la enfermedad con respecto a la presencia de anticuerpos antisulfátido y describe las concentraciones de anticuerpos antisulfátido que se encontraron en 124 pacientes (74 hombres y 50 mujeres) de 15 a 94 años de edad hospitalizados en el Servicio de Cardiología del Hospital Vargas de Caracas, durante el período del 1 de julio de 1993 al 30 de junio de 1995. Los títulos de anticuerpos antisulfátido se midieron con la técnica del inmunoensayo enzimático (ELISA) usando como antígeno cerebrósido sulfatado obtenido de cerebro de bovino. De los 124 pacientes estudiados, 39 (31,5\%) eran chagásicos y mostraron títulos de anticuerpos antisulfátido más altos que los 85 no chagásicos $(\mathrm{P}=0,0298)$ y que un grupo control de 28 sujetos aparentemente sanos $(\mathrm{P}=0,0035)$. Las concentraciones séricas de anticuerpos antisulfátido en pacientes con otras formas de cardiopatía también se compararon con las del grupo control y se encontraron títulos significativamente altos en sujetos con cardiopatía isquémica aguda $(\mathrm{P}=0,0049)$, cardiopatía valvular reumática $(\mathrm{P}=0,0075)$, cardiopatía isquémica crónica $(\mathrm{P}=0,0464)$ y bradiarritmias $(\mathrm{P}=0,0157)$, y valores significativamente bajos en sujetos con cardiopatía hipertensiva ( $\mathrm{P}=0,0367)$. Las concentraciones de dichos anticuerpos no se correlacionaron con variables clínicas o paraclínicas indicadoras del grado de afección cardíaca. Los resultados corroboran que los anticuerpos antisulfátido podrían desempeñar algún papel en la patogenia de la cardiomiopatía chagásica y de otras formas de cardiopatía y deben continuarse investigando hasta determinar su posible función en esos procesos.

Pese a que la tripanosomiasis americana o enfermedad de Chagas se man-

\footnotetext{
1 Hospital Vargas de Caracas, Caracas, Venezuela.

2 Instituto de Biomedicina, Caracas, Venezuela. La correspondencia y solicitudes de separatas deben enviarse a: José Luis Ávila, Instituto de Biomedicina, Apartado postal 4043, Caracas 1010 A, Venezuela.
}

tiene activa en extensas zonas de la Región de las Américas, aún no se ha podido encontrar un tratamiento específico, completamente eficaz y exento de efectos secundarios indeseables (1). Esta parasitosis es la primera causa de miocarditis en Centroamérica y América del Sur y la segunda causa de insuficiencia cardíaca en algunos países de esas subregiones (1-3).

De 10 a 20 años después de la fase aguda inicial de la infección por Trypanosoma cruzi, alrededor de $30 \%$ de los casos sufren lesiones cardíacas que se caracterizan por la escasez de parásitos en el miocardio, lo cual sugiere que 
el sistema inmunitario es el que desempeña el papel más importante como mecanismo causal de la enfermedad (4-7). La posibilidad se ve respaldada por la presencia de linfocitos productores de anticuerpos contra tejido cardíaco en el infiltrado inflamatorio del miocardio $(6,7)$. Además, en la enfermedad de Chagas pueden activarse diversos tipos de autoanticuerpos: contra las membranas plasmáticas de células de músculo estriado y de células endoteliales (8); contra la laminina (9) y contra los antígenos acídicos del citosol (10); anticuerpos que se ligan a los receptores betaadrenérgicos y colinérgicos muscarínicos de linfocitos y del miocardio (11); anticuerpos antineuronales; anticuerpos contra la proteína de superficie Fl-160 kDa (presente en el flagelo de tripomastigotes), y anticuerpos contra los péptidos 48X y $12 \mathrm{X}$ de esa proteína, que reaccionan con las proteínas de axones de nervios humanos $(12,13)$.

Ávila et al. han estudiado extensamente la reactividad sérica de diversos anticuerpos antiglucoproteínas y antiglucolípidos en pacientes con cardiomiopatía chagásica crónica (13), en quienes encontraron títulos elevados de anticuerpos contra residuos de galactosil(alfa1-3)galactosa (14-16), galactosil(alfa1-2)galactosa (17) y galactosil(alfa1-3)manosa (18). Esos residuos se han identificado tanto en la superficie de tripomastigotes de $T$. cruzi (14), como en proteínas de la membrana basal del endotelio vascular (19), en el intersticio celular del corazón de ratón (19) y en los nervios periféricos humanos (20). Los mismos investigadores también han informado que en pacientes con cardiopatía chagásica suele haber un aumento de la inmunorreactividad contra glucoproteínas de la membrana basal, tales como la laminina y el nidogen (21), y contra glucolípidos como el fosfoglucoinositol (22), los galactocerebrósidos (23) y los sulfátidos (24).

Los sulfátidos son los ésteres sulfatados de los galactocerebrósidos, moléculas formadas por una base de esfingosina, ácido graso y galactosa en una relación molar de 1:1:1 (25). Estos sulfátidos se encuentran presentes en la sustancia blanca cerebral y en la capa de mielina de los nervios periféricos, aunque también se encuentran en riñón, bazo, granulocitos, eritrocitos, plaquetas, estómago e intestino (25). Ávila et al. han descrito un anticuerpo natural antisulfátido que está presente en concentraciones bajas en el suero de todas las personas sanas estudiadas y que se mide por su interacción con el galactosil-cerámida-3-sulfato. Estos investigadores encontraron títulos elevados de anticuerpos antisulfátido en un total de 102 pacientes con infección crónica por T. cruzi, pero no en otros pacientes con leishmaniasis cutánea o visceral, infección por $T$. rangeli, malaria, toxoplasmosis $\mathrm{u}$ otras infecciones, helmintiasis o micosis (24). Como $T$. cruzi es rico en galactocerebrósido sulfatado, esos autores han propuesto que este glucolípido podría actuar como inmunógeno para producir concentraciones elevadas de anticuerpos antisulfátido, fenómeno que podría ser importante en la patogenia de los síntomas cardíacos o del sistema nervioso periférico que se han observado en la enfermedad de Chagas (24).

El propósito del presente estudio fue determinar si había diferencias entre pacientes con la enfermedad de Chagas y otros pacientes sin la enfermedad con respecto a la presencia de anticuerpos antisulfátido.

\section{MATERIALES Y MÉTODOS}

Pacientes. En el estudio se incluyó el total de 124 pacientes que fueron hospitalizados en el servicio de cardiología del Hospital Vargas de Caracas del 1 de julio de 1993 al 30 de junio de 1995. La edad de los pacientes oscilaba entre 15 y 94 años; 74 eran hombres y 50 , mujeres. Se tomó la historia clínica de cada paciente y se anotaron sus estadísticas vitales, antecedentes personales y familiares, y motivo de ingreso. Se registraron los resultados de un examen físico completo con énfasis en el sistema cardiovascular, así como los de un electrocardiograma estándar de 12 derivaciones, de una radiografía posteroanterior del tórax y de un ecocardiograma transtorácico.
Estas pruebas fueron realizadas por el personal del servicio de cardiología según técnicas estándar $(26,27)$. Durante el período de estudio, los pacientes se sometieron a una evaluación clínica y un estudio serológico cada 3 meses.

Las enfermedades cardiovasculares se diagnosticaron siguiendo los criterios de la New York Heart Association. Los pacientes se clasificaron en tres grupos básicos según el grado de afección cardíaca: en el grupo I se incluyó a los pacientes que no tenían síntomas o signos de cardiopatía, pero cuyas pruebas serológicas dieron resultados positivos a la enfermedad de Chagas; en el grupo II entraron los pacientes con pruebas serológicas positivas y alteraciones cardíacas chagásicas detectadas por electrocardiografía, ecocardiografía o radiografía; y en el grupo III, pacientes con pruebas serológicas positivas a enfermedad de Chagas y síntomas o signos de insuficiencia o dilatación cardíaca $(5,24,28)$.

También se incluyeron en el estudio como grupo control 28 voluntarios de la consulta externa del Instituto de Biomedicina (anexo al Hospital Vargas de (aracas), aparentemente sanos y de 16 a 50 años de edad (41 \pm 9 años de edad en promedio), sin antecedentes de hipertensión arterial, diabetes, tabaquismo o ningún tipo de cardiopatía y similares al promedio muestral en lo que respecta a situación socioeconómica.

A cada participante se le extrajeron 5 cc de sangre en un tubo seco para la separación del suero, que se envió al Laboratorio de Bioquímica del Instituto de Biomedicina, donde se mantuvo congelado a $-15^{\circ} \mathrm{C}$ por menos de 3 meses (29).

Anticuerpos antisulfátido. Los títulos séricos de anticuerpos antisulfátido se midieron por inmunoabsorción enzimática (ELISA), según las indicaciones exactas de Ávila et al. (24), usando como antígeno cerebrósido sulfatado obtenido de cerebro de bovino (galactosilcerámido-I3-sulfato) (24). Se fijó como límite superior para el nivel normal de anticuerpos antisulfátido la 
media más dos desviaciones estándar de los títulos de anticuerpos del grupo control $(806,68 \pm 342,03)$, o una densidad óptica $\left(\mathrm{DO}_{405}\right)$ de 1490 unidades.

Anticuerpos contra Trypanosoma cruzi. En cada muestra se midieron también por ELISA los niveles de anticuerpos contra T. cruzi, usando $1 \mu \mathrm{g}$ de antígeno (tripomastigotes obtenidos a partir de un cultivo de células Vero infectadas con T. cruzi en medio esencial mínimo con un $10 \%$ de suero fetal) y una dilución del suero de 1:800 en PBS-Tween 20, 0,05\%-1\% seroalbúmina bovina (técnica no publicada desarrollada por Ávila JL, Martínez A y Ávila A, Instituto de Biomedicina de Caracas; información recibida en octubre de 1993). Este ensayo ELISA tiene una sensibilidad de $99 \%$ y una especificidad de $100 \%$. Cada suero se analizó por triplicado y cada vez se incluyeron en la placa dos muestras positivas y cinco negativas que se usaron como controles.

Análisis estadístico. Las variables cualitativas se compararon por la prueba de ji cuadrado $\left(\chi^{2}\right)$ y las cuantitativas, según la prueba $t$ de Student o el análisis de la varianza. El nivel de significación estadística fue de $5 \%$.

\section{RESULTADOS}

De los 124 pacientes estudiados, 39 $(31,5 \%)$ dieron resultados positivos en las pruebas serológicas detectoras de la enfermedad de Chagas. De estos, 22 $(56 \%)$ eran hombres y $17(44 \%)$ mujeres, con un promedio de edad de $59 \pm$ 10 y $60 \pm 11$ años, respectivamente. De los sujetos con resultados serológicos negativos a la presencia de enfermedad de Chagas, 52 (61\%) eran varones y $33(39 \%)$ mujeres, con un promedio de edad de $55 \pm 16$ y $61 \pm 17$ años, respectivamente.

En cuanto a las características clínicas, $82 \%$ de los pacientes positivos refirieron como factores epidemiológicos que intervienen en la enfermedad de Chagas haber vivido en el campo, haber vivido en casa de barro con techo de palma, conocer el $R$. prolixus o haber recibido su picadura $(P \leq 0,001)$ $y$ haber ingresado en el hospital por insuficiencia cardíaca $(P \leq 0,02)$. Asimismo presentaron en el electrocardiograma bloqueo de la rama derecha del haz de His más hemibloqueo anterior izquierdo - tanto aislado $(P \leq 0,01)$ como asociado con prolongación del intervalo PR $(P \leq 0,02)$-, hipocinesia general $(P \leq 0,001)$, aneurisma apical $(P \leq 0,05)$ y fracción de eyección baja $(P \leq 0,001)$ en el ecocardiograma. El pulso y la tensión arterial sistólica y diastólica fueron significativamente más bajos en los pacientes chagásicos que en los no chagásicos, mientras que el intervalo QT fue significativamente más largo en los primeros que en los segundos $(P=0,02)$. En los pacientes sin enfermedad de Chagas se observaron con mayor frecuencia el dolor torácico $(P \leq 0,05)$ y el infarto agudo del miocardio $(P \leq 0,05)$. En los que tenían la enfermedad, solo uno $(2,6 \%)$ refirió cinco o más factores de riesgo de enfermedad coronaria, frente a $14(16,5 \%)(P \leq 0,001)$ de los no chagásicos.

La muestra para la determinación de anticuerpos antisulfátido se tomó a los $9 \pm 6$ días de estar hospitalizados los pacientes. Los resultados mostraron que las concentraciones de anticuerpos antisulfátido eran significativamente más elevadas en los pacientes chagásicos que en los pacientes no chagásicos $(P=0,0298)$ y que en los controles $(P=0,0035)$. Además, los pacientes no chagásicos tenían títulos de anticuerpos significativamente más altos que los controles $(P=0,0257)$ (cuadro 1).

Al compararse con los del grupo control y desglosarse según el tipo de cardiopatía, los títulos séricos de anticuerpos antisulfátido resultaron significativamente más altos en los sujetos con diagnóstico de cardiopatía isquémica aguda y crónica, cardiopatía valvular reumática y bradiarritmias aisladas (cuadro 2). En cambio, los títulos de anticuerpos antisulfátido fueron significativamente más bajos en el grupo con cardiopatía hipertensiva. No se observaron diferencias significativas individuales entre los controles y los pacientes con cardiopatía mixta de tipo isquémico e hipertensivo, otras formas de cardiopatías tales como las de origen congénito y valvulopatías no reumáticas.

En los pacientes que tuvieron títulos de anticuerpos superiores al valor de la densidad óptica que se estableció como normal (1 490 unidades) se diagnosticaron las cardiopatías siguientes: cardiopatía isquémica aguda en 16 pacientes (50\%); bradiarritmias en 4 pacientes (50\%); cardiopatía valvular reumática en 10 pacientes $(40 \%)$, y cardiopatía isquémica crónica en 20 pacientes $(10 \%)$. Ninguno de los pacientes con cardiopatía congénita, hipertensiva o mixta isquémica e hipertensiva tuvo concentraciones elevadas de anticuerpos antisulfátido.

CUADRO 1. Títulos de anticuerpos antisulfátido detectados por la prueba ELISA en pacientes con enfermedad de Chagas y pacientes sin la enfermedad hospitalizados en el Servicio de Cardiología del Hospital Vargas de Caracas, Venezuela, 1 de julio de 1993 a 30 de junio de 1995

\begin{tabular}{|c|c|c|c|c|c|}
\hline \multirow[b]{2}{*}{ Sujetos (No.) } & \multicolumn{3}{|c|}{$\begin{array}{l}\text { Títulos de anticuerpos } \\
\text { antisulfátido }^{\mathrm{a}}\end{array}$} & \multirow[b]{2}{*}{$P^{c}$} & \multirow[b]{2}{*}{$P^{d}$} \\
\hline & (Media & \pm & $\left.\mathrm{DE}^{\mathrm{b}}\right)$ & & \\
\hline Controles (28) & 806,68 & \pm & 342,03 & - & - \\
\hline No chagásicos (85) & 1125,04 & \pm & 703,02 & 0,0257 & - \\
\hline Chagásicos (39) & 1414,76 & \pm & 1072,10 & 0,0035 & 0,0298 \\
\hline
\end{tabular}


CUADRO 2. Relación de los títulos séricos de anticuerpos antisulfátido detectados por la prueba ELISA en controles y pacientes con distintas formas de cardiopatía hospitalizados en el Servicio de Cardiología del Hospital Vargas de Caracas, Venezuela, 1 de julio de 1993 a 30 de junio de 1995

\begin{tabular}{|c|c|c|c|c|}
\hline \multirow[b]{2}{*}{ Diagnóstico (No.) } & \multicolumn{3}{|c|}{$\begin{array}{l}\text { Títulos de anticuerpos } \\
\text { antisulfátido }^{\mathrm{a}}\end{array}$} & \multirow[b]{2}{*}{$P$} \\
\hline & (Media & \pm & $\left.\mathrm{DE}^{\mathrm{b}}\right)$ & \\
\hline Controles (28) & 806,68 & \pm & 342,03 & \\
\hline Enfermedad de Chagas crónica (39) & 1414,76 & \pm & 1072,10 & 0,0035 \\
\hline Cardiopatía isquémica aguda (16) & 1348,64 & \pm & 576,69 & 0,0049 \\
\hline Cardiopatía valvular reumática (11) & 1236,20 & \pm & 658,21 & 0,0075 \\
\hline Cardiopatía isquémica crónica (22) & 1050,89 & \pm & 402,97 & 0,0464 \\
\hline Cardiopatía hipertensiva (9) & 518,13 & \pm & 296,45 & 0,0367 \\
\hline Bradiarritmias aisladas (4) & 1675,25 & \pm & 408,14 & 0,0157 \\
\hline Cardiopatía mixta (13) & 741,36 & \pm & 670,84 & $\mathrm{NS}^{\mathrm{c}}$ \\
\hline Otro (10) & 1116,43 & \pm & 1043,11 & NS \\
\hline
\end{tabular}

a Unidades de densidad óptica a $405 \mathrm{~mm}$.

b Desviación estándar.

c No significativo.

En los pacientes con enfermedad de Chagas se encontraron algunas formas comunes de cardiopatía, pero la más frecuente fue la de tipo chagásica única. Al comparar estadísticamente las concentraciones de anticuerpos antisulfátido según el tipo de cardiopatía de los pacientes, se observaron diferencias significativas entre las de pacientes con cardiopatías de tipo hipertensivo y las de pacientes con cardiopatía chagásica única, cuyos valores fueron más altos $(P=$ 0,0159). Asimismo, dichos valores fueron más bajos en pacientes chagásicos con diabetes $(P=0,0108)$ (cuadro 3$)$. De hecho, el porcentaje de pacientes chagásicos con concentraciones de anticuerpos anormalmente altas aumentó de 36 a 54\% cuando se excluyó del análisis a los pacientes con cardiopatía isquémica crónica, a pacientes hipertensos y diabéticos, y a los que tenían antecedentes o presencia de infarto del miocardio, cor pulmonale o valvulopatías.

Cuando se analizaron las características clínicas de los pacientes, se encontraron diferencias significativas entre los niveles de anticuerpos antisulfátido solamente en pacientes con antecedentes de cardiopatías o aumento del espesor ventricular izquierdo por ecocardiograma (cuadro 4). No se encontraron diferencias significativas según

\section{DISCUSIÓN}

La inmunorreactividad de los anticuerpos antisulfátido en los pacientes chagásicos fue significativamente más alta que en los no chagásicos, y mucho más alta aún que en los integrantes del grupo control. Los títulos elevados de anticuerpos antisulfátido (24) que se describen en estudios sobre la enfermedad de Chagas crónica también se encuentran en otras enfermedades, tales como las miocardiopatías dilatadas idiopáticas (24), la artritis reumatoide (29), la hepatitis crónica activa (30) y la púrpura trombocitopénica idiopática (31). Sin embargo, todavía no se conoce la manera en que se inicia la respuesta autoinmunitaria de los anticuerpos antisulfátido. En el caso de la cardiopatía chagásica, se ha propuesto la teoría del "mimetismo molecular" (13), ya que T. cruzi es muy rico en glucolípidos y sulfátidos capaces de inducir una respuesta inmunitaria, además de inducir la expresión de estas moléculas en células humanas y de intensificar una respuesta de anticuerpos ya existente (13). Puede haber dos tipos de mimetismo molecular. El mimetismo molecular natural se refiere a la presencia de antígenos con reacción cruzada en el código del genoma, tanto del huésped como del parásito. El mimetismo molecular adquirido se refiere a la alteración de lo propio, cuando el parásito induce la

CUADRO 3. Relación entre los títulos de anticuerpos antisulfátido detectados por la prueba ELISA en pacientes con enfermedad de Chagas y los títulos de pacientes chagásicos con otros diagnósticos adicionales, en pacientes hospitalizados, Servicio de Cardiología del Hospital Vargas de Caracas, Venezuela, 1 de julio de 1993 a 30 de junio de 1995

\begin{tabular}{|c|c|c|c|c|}
\hline \multirow[b]{2}{*}{ Diagnóstico (No.) } & \multicolumn{3}{|c|}{$\begin{array}{c}\text { Títulos de anticuerpos } \\
\text { antisulfátidoa }\end{array}$} & \multirow[b]{2}{*}{$P$} \\
\hline & (Media & \pm & $\left.\mathrm{DE}^{\mathrm{b}}\right)$ & \\
\hline Enfermedad de Chagas (13) & 1736,7 & \pm & 1040,1 & \\
\hline Chagas y diabetes mellitus tipo II (6) & 642,0 & \pm & 356,1 & 0,0108 \\
\hline Chagas y cardiopatía hipertensiva (8) & 829,3 & \pm & 409,5 & 0,0159 \\
\hline Chagas y cardiopatía isquémica crónica (7) & 1345,6 & \pm & 1047,2 & NS ${ }^{c}$ \\
\hline Chagas y cardiopatía isquémica aguda (2) & 2630,0 & \pm & 1863,9 & NS \\
\hline Chagas y valvulopatía reumática crónica (2) & 1808,5 & \pm & 1894,3 & NS \\
\hline Chagas y cor pulmonale crónico (1) & 107,0 & & & - \\
\hline
\end{tabular}


CUADRO 4. Relación entre niveles de anticuerpos antisulfátido y hallazgos clínicos con diferencias estadísticamente significativas, en pacientes hospitalizados en el Servicio de Cardiología del Hospital Vargas de Caracas, Venezuela, 1 de julio de 1993 a 30 de junio de 1995

\begin{tabular}{|c|c|c|}
\hline & \multicolumn{2}{|c|}{ Títulos de anticuerpos antisulfátido ${ }^{a}$} \\
\hline & $\begin{array}{c}\text { Chagásicos } \\
\text { (Media } \pm \mathrm{DE}^{\mathrm{b}}(\text { No.))) }\end{array}$ & $\begin{array}{c}\text { No chagásicos } \\
\text { (Media } \pm \mathrm{DE} \text { (No.)) }\end{array}$ \\
\hline \multicolumn{3}{|c|}{ Antecedentes de cardiopatía } \\
\hline $\begin{array}{l}\text { Positivos } \\
\text { Negativos } \\
P\end{array}$ & $\begin{array}{c}1221,8 \pm 925,8(30) \\
2085,4 \pm 1268,7 \quad(9) \\
0,0484\end{array}$ & $\begin{array}{c}1006,3 \pm 646,0(66) \\
1420,5 \pm 597,8(19) \\
0,0231\end{array}$ \\
\hline \multicolumn{3}{|c|}{$\begin{array}{l}\text { Hipertrofia ventricular izquierda } \\
\text { por ecocardiograma }\end{array}$} \\
\hline $\begin{array}{l}\text { Presente } \\
\text { Ausente } \\
P\end{array}$ & $\begin{array}{c}845,6 \pm 680,0 \quad(9) \\
1635,1 \pm 1122,6(30) \\
0,0184\end{array}$ & $\begin{array}{r}929,2 \pm 666,0(37) \\
1169,0 \pm 604,7(48) \\
\text { NS }^{c}\end{array}$ \\
\hline
\end{tabular}

a Unidades de densidad óptica a $405 \mathrm{~mm}$.

${ }^{b}$ Desviación estándar.

${ }^{\mathrm{C}}$ No significativo.

expresión de un determinante antigénico concreto en las células infectadas del huésped o cuando hay inserción de moléculas del parásito en las células del huésped (13).

En el caso de la infección por T. cruzi, el antígeno podría adherirse durante el período en que el tripomastigote penetra en las células (nerviosas o musculares) del huésped humano. Una vez dentro del fagolisosoma de estas células, los antígenos de T. cruzi podrían llegar a la membrana celular e inducir la expresión de neoantígenos (13).

Además de la teoría del "mimetismo molecular", se ha propuesto la del "cambio de repertorio". Según esta teoría, la infección natural estimula la capacidad autorreactiva intrínseca de una serie de familias de células $\mathrm{T}$ y $\mathrm{B}$, de tal manera que al ocurrir la activación policlonal en la fase aguda de la infección (32-35), se modificaría por algún mecanismo la red idiotípica supresora. Ello permitiría la respuesta de células $T$ o $B$ autorreactivas sin mucha supresión y por largo tiempo (34), con producción de anticuerpos tanto específicos contra el parásito como no específicos, incluidos los autoanticuerpos $(36,37)$ y entre ellos los de tipo antisulfátido.

En el "mimetismo molecular" la respuesta autoinmunitaria es específica para cada órgano y de orden oligoclonal. Así, en las lesiones tisulares, las células $\mathrm{T}$ efectoras se activarían por acción de una serie limitada de sustancias unidas a las moléculas del complejo mayor de histocompatibilidad $(36,37)$. En el segundo modelo, el del "cambio de repertorio", no hay explicación a priori para las lesiones localizadas en los tejidos muscular y nervioso, aunque podrían depender de la activación de ciertas familias de genes por la infección por T. cruzi. Según este modelo, la respuesta autoinmunitaria debería ser más heterogénea. Los diversos grupos de genes codificadores de los receptores de células $\mathrm{T}$ reconocerían varios péptidos diferentes, unidos al complejo mayor de histocompatibilidad. En la cardiopatía chagásica — dada la persistencia del parásito en el organismo, protegido por las propias células de los tejidos muscular y nervioso y por los macrófagos-, $T$. cruzi podría mantener activa la expresión de antígenos capaces de alterar de forma prolongada la función de las células T o B $(13,36,37)$.

Si bien en un trabajo previo se informó de la presencia de concentraciones elevadas de anticuerpos antisulfátido en todos los pacientes chagásicos (24), en el presente estudio los anticuerpos se encontraron en solo
$36 \%$ de la muestra. Es difícil comparar los resultados obtenidos en ambos estudios, ya que en este se encontraron trastornos asociados que disminuyen los títulos de anticuerpos, como cardiopatía hipertensiva y diabetes mellitus tipo II. Estas afecciones se habían excluido del primer estudio (24), en el cual se realizó angiografía coronaria en todos los pacientes con cardiopatía chagásica, descartándose de ese grupo a los que tenían indicios de enfermedad coronaria. Además, el promedio de edad fue menor en el estudio efectuado anteriormente.

El hallazgo de una relación entre las concentraciones elevadas de anticuerpos antisulfátido y antecedentes de cardiopatía sugiere que los títulos aumentan cuando se presentan episodios agudos, como el infarto del miocardio, y que tienden a disminuir con el tiempo. Sin embargo, esto no se puede demostrar mediante el presente trabajo, ya que se requieren estudios de seguimiento.

Cabe notar que los pacientes chagásicos tuvieron valores más bajos de la tensión arterial y del pulso, incluso después de excluirse los trastornos del ritmo que se describen en la enfermedad de Chagas, como bradicardia sinusal, enfermedad del nodo senoauricular y bloqueos auriculoventriculares (38). Esto sugiere algún tipo de trastorno del sistema nervioso autónomo $(39,40)$, tal como el que se ha descrito en los pacientes con insuficiencia cardíaca (41), cardiopatía isquémica (42) y diabetes (43). Sin embargo, no se encontró ninguna relación entre los valores de la tensión arterial o de la frecuencia cardíaca y las concentraciones de anticuerpos antisulfátido, aunque se ha descrito un incremento de los títulos de anticuerpos contra distintos antígenos de células nerviosas en pacientes con la enfermedad de Chagas, por lo que se plantea la posibilidad de que estos anticuerpos ocasionen la neuropatía por bloqueo progresivo de las terminaciones nerviosas $(13,44,45)$.

La falta de una relación entre las concentraciones de anticuerpos antisulfátido y el grado de afección cardíaca ya se había señalado (24). Una de 
las explicaciones postuladas es que las concentraciones de anticuerpos antisulfátido pueden tener alguna relación con el grado de alteración de los nervios periféricos que existe en la enfermedad de Chagas debido a la alta densidad de sulfátido en la vaina de mielina de estos nervios (25), y que el grado de esas alteraciones neurológicas guarda relación con la cardiopatía (24, 39, 40, 45). Sin embargo, también se encuentran títulos elevados de anticuerpos en otras formas de cardiopatía que no se acompañan del grado de trastorno neurológico observado en la enfermedad de Chagas, lo cual sugiere una relación más directa con el daño del músculo cardíaco.

En nuestro estudio se hospitalizó por dolor torácico a dos pacientes chagásicos que en los estudios de enzimas séricas y en las electrocardiografías mostraron cambios evolutivos compatibles con infarto agudo del miocardio. Además, $22(17,7 \%)$ de los pacientes estudiados refirieron antecedentes de infarto del miocardio o del dolor torácico característico de enfermedad coronaria. Las electrocardiografías o ecocardiografías de esos pacientes revelaron la presencia de cardiopatía isquémica, si bien no se realizaron angiografías coronarias para demostrar la presencia de enfermedad coronaria arteriosclerótica. Es de esperarse que estos dos trastornos clínicos coexistan, ya que son frecuentes en nuestro medio, aunque las lesiones podrían tener su origen en enfermedad de tipo microvascular o inflamatorio $(4,5)$. No obstante, entre los pacientes chagásicos hubo solo un pequeño porcentaje de pacientes con dolor torácico, infarto agudo del miocardio y factores de riesgo de enfermedad coronaria. Esto último podría explicar la baja prevalencia de cardiopatía isquémica en pacientes chagásicos, si bien se ha observado que algunas interleuquinas - como la interleuquina-3, el factor estimulante del crecimiento de granulocitos y macrófagos, y el factor de crecimiento de monocitos, que podrían estar elevados en los chagásicos-, podrían disminuir los valores de colesterol y de la lipoproteína de densidad baja (LDL) y, por lo tanto, el riesgo de arteriosclerosis $(46,47)$.

En comparación con los del grupo control, los títulos de anticuerpos antisulfátido fueron mayores en los pacientes con diagnóstico de cardiopatía isquémica, tanto de forma crónica como aguda. En la forma aguda los valores de anticuerpos fueron incluso más altos, aunque la diferencia no fue estadísticamente significativa. Si bien los mecanismos fisiopatológicos de la cardiopatía isquémica aguda y crónica son diferentes, la presencia de concentraciones elevadas de anticuerpos antisulfátido podría explicar los dos mecanismos. En el proceso arteriosclerótico intervienen factores inmunitarios y desempeñan un papel importante los macrófagos, linfocitos y plaquetas (48). Se sabe que las plaquetas son ricas en sulfátidos (25), de modo que al existir niveles elevados de anticuerpos antisulfátido, estos podrían adherirse a las plaquetas y ocasionar su activación y desgranulación, desencadenando así el proceso trombótico, o activar los macrófagos y linfocitos, desencadenando una respuesta inflamatoria local (48). Además, ante cierta concentración de anticuerpos, este proceso podría intensificarse hasta el punto de ocluir completamente la luz del vaso coronario, lo que explicaría el infarto agudo del miocardio (48). En ese caso, quedaría por explicar por qué se activa la respuesta de anticuerpos antisulfátido.

En los pacientes con cardiopatía valvular reumática se encontraron títulos de anticuerpos antisulfátido significativamente altos, quizá debido a la exposición de antígenos en el músculo cardíaco, producto del daño de origen inmunitario desencadenado por la infección estreptocócica. También podría formar parte de una reacción cruzada entre antígenos de la membrana celular estreptocócica y el sarcolema del miocardio, como se ha demostrado con otros antígenos en pacientes con fiebre reumática, en cuyo suero se han encontrado anticuerpos con capacidad para unirse a los ganglios basales de pacientes con corea $(49,50)$.
La unión de anticuerpos con el tejido cardíaco puede contribuir al daño del miocardio mediante la citotoxicidad por ellos inducida, la activación del complemento, o la liberación de sustancias citotóxicas por los macrófagos. En la enfermedad de Chagas no se sabe claramente cómo se produce la lesión cardíaca, si bien podría producirse por lesión de las células ganglionares parasimpáticas, por lesión directa del músculo cardíaco, o por ambos mecanismos $(13,36,37,40)$.

Se desconoce en qué medida la destrucción celular puede exponer a sustancias antigénicas capaces de desencadenar una respuesta autoinmunitaria, como podría ocurrir en la cardiopatía isquémica y en la cardiopatía valvular reumática. Asimismo, por acción de algún agente infeccioso (viral, por ejemplo), se puede producir el cambio de antígenos o la exposición por las células del miocardio de antígenos capaces de provocar autoinmunidad (51).

Llaman la atención las bajas concentraciones de anticuerpos antisulfátido en pacientes con cardiopatía hipertensiva, lo cual podría estar vinculado con una mayor concentración o expresión del antígeno sin una relación estrecha con la masa de músculo cardíaco. No había sido notificada previamente la relación entre concentraciones bajas de anticuerpos antisulfátido y la hipertensión arterial o la diabetes mellitus tipo II en pacientes chagásicos. Sin embargo, vale la pena mencionar que recientemente se han encontrado títulos elevados de anticuerpos antisulfátido en pacientes con diabetes mellitus tipo I (52). Los valores elevados de dichos anticuerpos en pacientes con pruebas serológicas negativas a la enfermedad de Chagas y bradiarritmias podrían vincularse con la presencia de otras formas de cardiopatía en las que se observó aumento de esos valores, como en la cardiopatía isquémica o lesión de alguna zona particular del tejido cardíaco.

La detección de títulos elevados de anticuerpos antisulfátido en pacientes con otras formas de cardiopatía sugiere la posibilidad de que estos 
anticuerpos estén involucrados en la patogenia de la cardiopatía chagásica y posiblemente de las otras formas de cardiopatía $(13,24)$. Aun así, todavía falta determinar el papel que desempeñan los anticuerpos antisulfátido en esos procesos.
Agradecimiento. Los autores expresan su agradecimiento a todo el personal del Laboratorio de Bioquímica del Instituto de Biomedicina y del Servicio de Cardiología del Hospital Vargas de Caracas, y muy especialmente a los doctores Eduardo Morales Bri- ceño y Aaron Cohen por su valiosa colaboración.

Este trabajo fue financiado por el Consejo Nacional de Investigaciones Científicas y Tecnológicas (CONICIT), Caracas, Venezuela, proyecto S1-2699.

\section{REFERENCIAS}

1. Kirchhoff LV. American trypanosomiasis (Chagas' disease): a tropical disease now in the United States. N Engl J Med 1993;329: 639-644.

2. García R. Diagnósticos de egreso en el Servicio de Cardiología del Hospital Vargas de Caracas. En: XVIII Congreso Venezolano de Cardiología, Caraballeda, Venezuela, 1995. p. 57.

3. Hayes R, Schofield C. Estimación de las tasas de incidencia de infecciones y parasitosis crónicas a partir de la prevalencia: la enfermedad de Chagas en América Latina. Bol Oficina Sanit Panam 1990;108(4):308-316.

4. Suárez J, Puigbó JJ, Nava-Rhode J, Valero J, Gil Yépez C. Estudio anatomopatológico de 210 casos de miocardiopatías en Venezuela. Acta Med Venezolana 1968;15:320-330.

5. Puigbó JJ, Zisman E. Descripción y evaluación crítica de la patogenia de las lesiones cardíacas en la enfermedad de Chagas. Acta Med Venezolana 1968;15:310-319.

6. Cabeza-Meckert P, Chambo J, Laguens R. Presence of cells producing antiheart autoantibodies in the inflammatory infiltrate of chronic chagasic myocarditis. Clin Immunol Immunopathol 1991;60:137-144.

7. Petry K, Eisen H. Chagas' disease: a model for the study of autoimmune disease. Parasitol Today 1989;5:111-116.

8. Cossio PM, Laguens RP, Diez C. Chagasic cardiopathy: antibodies reacting with plasma membrane of striated muscle and endothelial cells. Circulation 1974;50:1252-1259.

9. Szarfman A, Terranova VP, Renard SL, Foidart JM, Lima MF, Scheinman JL, et al. Antibodies to laminin in Chagas' disease. $J$ Exp Med 1982;155:1161-1171.

10. Gea S, Gruppi A, Basso B, Menso E, VotteroCima E. Antibodies to Trypanosoma cruzi cytosol acidic antigens (FIV) in Chagas' disease recognize parasite cell surface and human heart epitopes. J Clin Lab Immunol 1990;31:183-187.

11. Sterin-Borda LJ, Borda ES. Interacción del sistema nervioso autónomo con linfocitos y anticuerpos en la patogenia de la enfermedad de Chagas. En: Organización Panamericana de la Salud. La enfermedad de Chagas y el sistema nervioso. Washington, DC: OPS; 1994. pp. 317-338. (Publicación científica 547).

12. Van Voorhis WC, Schlekewy L, Trong HL. Molecular mimicry by Trypanosoma cruzi: the Fl-160 epitope that mimics mammalian nerve can be mapped to a 12-amino acid peptide. Proc Natl Acad Sci USA 1991;88:5993-5997.

13. Ávila JL. Enfermedad de Chagas: evidencias de mimetismo molecular entre Trypanosoma cruzi y tejidos nerviosos del huésped. Rev Facultad Med (Universidad Central de Venezuela) 1995;18:32-46.

14. Ávila JL, Rojas M, Galili U. Immunogenic gal(alfa1-3)gal carbohydrate epitopes are present on pathogenic American Trypanosoma and Leishmania. J Immunol 1989;142:2828-2834.

15. Ávila JL, Rojas M, Towbin H. Serological activity against galactosyl(alfa1-3)galactose in sera from patients with several kinetoplastida infections. J Clin Microbiol 1988;26:126-132.

16. Ávila JL, Rojas M, Carrasco H. Increased galactosyl(alfa1-3)galactose antibody levels in patients with different clinical stages of tropical chronic dilatatory cardiomyopathies. Immunology (Life Sci Adv) 1991;10:1530-1537.

17. Ávila JL, Rojas M, Velázquez-Ávila G. Characterization of a natural human antibody with galactosyl(alfa1-2)galactose specificity that is present at high titers in chronic Trypanosoma cruzi infection. Am J Trop Med Hyg 1993;42: 113-131.

18. Ávila JL, Rojas M. A galactosyl(alfa1-3)mannose epitope on phospholipids of Leishmania mexicana and L. braziliensis is recognized by trypanosomatid-infected human sera. I Clin Microbiol 1990;28:1530-1537.

19. Cossio P, Diez C, Szarfman A, Kreutzer E, Candiolo B, Arana RM. Chagasic cardiopathy on a serum gamma globulin factor which reacts with endocardium and vascular structures. Circulation 1974;49:13-21.

20. Gulati AK, Zalewski AA, Shama KB Ogrowsky D, Sohal GS. A comparison of lectin binding in rat and human peripheral nerve. I Histochem Cytochem 1986;34:1487-1494.

21. Ávila JL, Rojas M, Velázquez-Ávila G, Von der Mark H, Timpl R. Antibodies to basement membrane protein nidogen in Chagas' disease and American cutaneous leishmaniasis. J Clin Microbiol 1986;24:775-778.

22. Ávila JL, Rojas M, Acosta A. Glycoinositol phospholipids from American Leishmania and Trypanosoma spp: partial characterization of the glycan cores and the human humoral immune response to them. I Clin Microbiol 1991:29:2305-2312

23. Ávila JL, Rojas M. Elevated cerebroside antibody levels in human visceral and cutaneous leishmaniasis, Trypanosoma rangeli infection and chronic Chagas' disease. Am J Trop Med Hyg 1990;43:52-60.

24. Ávila JL, Rojas M, Carrasco H. Elevated levels of antibodies against sulphatide are present in all chronic chagasic and dilated cardiomyopathy sera. Clin Exp Immunol 1993;92:460-465.

25. Roberts DD. Sulfatide-binding proteins. Chem Phys Lipid 1986;42:173-183.

26. Acquatella $\mathrm{H}$, Schiller N, Puigó JJ, Giordano $\mathrm{H}$, Suárez JA, Casal H, et al. M-mode and twodimensional echocardiography in chronic Chagas' heart disease. Circulation 1980;62: 787-799.

27. Aurigemma G, Gaasch W, Villegas B, Meyer T. Noninvasive assessment of left ventricular mass, chamber volume and contractile function. Curr Probl Cardiol 1995;6:380-394.

28. Carrasco HA, Barboza JS, Inglessis G, Fuenmayor A, Molina C. Left ventricular cineangiography in Chagas' disease: detection of early myocardial damage. Am Heart J 1982;104:595-602.

29. Aotsuka S, Okawa-Takatsuji M, Uwatoko S, Yokohari R, Ikeda Y, Toda G. Antibodies against sulphatide in sera from patients with autoimmune rheumatic diseases. Clin Exp Immunol 1992;87:438-443.

30. Toda G, Ikeda Y, Kashiwagi M, Iwamori M, Oka $\mathrm{H}$. Hepatocyte plasma membrane glycosphingolipid reactive with sera from patients with autoimmune chronic active hepatitis: its identification as sulfatide. Hepatology 1990;12:664-670.

31. Van Vliet HHDM, Kappers-Klunne MC, Van Der Hel JWB, Abels J. Antibodies against glycosphingolipids in sera of patients with idiopathic thrombocytopenic purpura. Brit J Haematol 1987;67:103-108.

32. Ortiz-Ortiz L, Parks DE, Rodríguez M, Weigle WO. Polyclonal B lymphocyte activation during Trypanosoma cruzi infection. J Immunol 1980;124:121-125.

33. Minoprio PM, Eisen H, Formi L, D'Imperio Lima MR, Joskowicz M, Coutinho A. Polyclonal responses to murine Trypanosoma cruzi infection: I, Quantitation of both $\mathrm{T}$ and B responses. Scand J Immunol 1986;24:661-668.

34. D'Imperio Lima MR, Eisen H, Minoprio P, Joskowicz M, Coutinho A. Persistence of polyclonal B cell activation with undetectable parasitemia in late stages of experimental Chagas' disease. J Immunol 1986;137:353-356. 
35. Spinella S, Liegard P, Hontebeyrie-Joskowicz M. Trypanosoma cruzi: predominance of IgG2a in nonspecific humoral response during experimental Chagas' disease. Exp Parasitol 1992;74:46-56

36. Hontebeyrie-Joskowicz M. Inmunidad humoral y celular en la infección y enfermedad por Trypanosoma cruzi. En: Organización Panamericana de la Salud. La enfermedad de Chagas y el sistema nervioso. Washington, DC: OPS; 1994. pp. 281-304. (Publicación científica 547).

37. Dos Reis G, Gómez N, López M. Autoinmunidad y activación de linfocitos $\mathrm{T}$ en la enfermedad de Chagas crónica. En: Organización Panamericana de la Salud. La enfermedad de Chagas y el sistema nervioso. Washington, DC: OPS; 1994. pp. 305-316. (Publicación científica 547).

38. Hernández-Pieretti O, Lozano JR, Urbina A, Rodríguez R. Sick sinus syndrome in chronic Chagas' heart disease. Am J Cardiol 1974;33: 144-149.

39. Iosa D. Cardioneuropatía chagásica crónica: patogenia y tratamiento. En: Organización Panamericana de la Salud. La enfermedad de Chagas y el sistema nervioso. Washington, DC: OPS; 1994. pp. 109-159. (Publicación científica 547).

40. Palmero H, Caeiro T, Iosa D. Effect of Chagas' disease on arterial blood pressure. Am Heart J 1979;97(1):38-42.
41. Floras J. Clinical aspects of sympathetic activation and parasympathetic withdrawal in heart failure. J Am Coll Cardiol 1993;22(4, supl A):72-84.

42 Lombardi F, Sandrone G, Pernpruner S, Robert B. Heart rate variability as an index of sympathovagal interaction after acute myocardial infarction. Am J Cardiol 1987;60:1239-1241.

43. Ewing D, Martyn C,Young R, Clarke B. The value of cardiovascular autonomic function tests: 10 years experience in diabetes. Diabetes Care 1985;8:491-498.

44. Gazzinelli R, Leme V, Cancado J, Gazzinelli G, Scharfstein J. Identification and partial characterization of Trypanozoma cruzi antigens recognized by $\mathrm{T}$ cells and immune sera from patients with Chagas' disease. Infect Immun 1990;58:1437-1444.

45. Gea S, Ordóñez P, Cerban F, Iosa D, Chizzolini C, Vottero-Cima E. Chagas' cardioneuropathy: association of anti-Trypanosoma cruzi and anti-sciatic nerve antibodies. Am I Trop Med Hyg 1993;49:581-588.

46. Postmus PE, Gietema JA, Damsma O, Dittmer $\mathrm{R}$, Pellegrini J. Effects of recombinant human interleukin-3 in patients with relapsed smallcell lung cancer treated with chemotherapy: a dose-finding study. J Clin Oncol 1992;10: 1131-1140.

47. Ishibashi $\mathrm{S}$, Inaba $\mathrm{T}$, Shimano $\mathrm{H}$, Okuna $\mathrm{S}$, Higashi K. Monocyte colony-stimulating factor enhances uptake and degradation of ace- tylated low density lipoproteins and cholesterol esterification in human monocytederived macrophages. J Biol Chem 1990;265: 14109-14117.

48. Fuster V, Badimon L, Badimon J, Chesebro J. The pathogenesis of coronary artery disease and the acute coronary syndromes. $\mathrm{N} \mathrm{Engl} \mathrm{J}$ Med 1992;326:242-250.

49. Goldstein I, Halpern B, Robert L. Immunologic relationship between streptococcus A polysaccaride and the structural glycoprotein of heart valve. Nature 1967;213:44.

50. Zabriskie JB, Freimer EH. The immunological relationship between the group A streptococcus and mammalian muscle. J Exp Med 1966; 124:661-678.

51. Herskowitz A, Neumann D, Ansari A. Concepts of autoimmunity applied to idiopathic dilated cardiomyopathy. J Am Coll Cardiol 1993;22:1385-1388.

52. Buschard K, Josefsen K, Horn T, Fredman P. Sulphatide and sulphatide antibodies in insulin-dependent diabetes mellitus. Lancet $1993 ; 342: 840$

Manuscrito recibido el 3 de diciembre de 1996 y aceptado para publicación en versión revisada el 21 de julio de 1997.
ABSTRACT

Antisulfatide antibody titers in
patients with chronic Chagas
heart disease and other
forms of heart disease

A specific treatment for Chagas' disease has not yet been discovered, even though the condition is endemic in large parts of the Region of the Americas. Earlier studies have addressed the possibility that the sulfatide galactocerebroside in Trypanosoma cruzi behaves as an immunogen involved in the production of the high antisulfatide antibody levels found in patients with chronic infestation with the parasite. This may be an important factor in the pathogenesis of the cardiac symptoms and peripheral neuropathy seen in Chagas' disease, which is the most important cause of myocarditis in Central and South America and the second most important cause of heart failure in several of the countries located in these subregions. The present study was conducted in order to ascertain whether patients with Chagas' disease and other patients not afflicted with the ailment differ insofar as the presence of antibodies against sulfatide is concerned, and it describes antisulfatide antibody levels in 124 hospital patients (74 men and 50 women) between the ages of 15 and 94 who were in the cardiology unit of Vargas Hospital in Caracas from 1 July to 30 June 1995. Antisulfatide antibody titers were determined by means of enzyme-linked immunosorbent assays (ELISA) and the antigen employed was sulfatide cerebroside obtained from bovine brain tissue. Of the 124 patients under study, 39 (31,5\%) suffered from Chagas' disease and had antisulfatide antibody levels higher than those detected in patients without Chagas $(P=0,0298)$ and in 28 seemingly healthy controls $(P=0,0035)$. Serum levels of antisulfatide antibodies in patients with other forms of heart disease were also compared with those seen in the control group, and significantly higher levels were found in patients with acute ischemic heart disease $(P=0,0049)$, rheumatic valvular heart disease $(P=0,0075)$, chronic ischemic heart disease $(P=0,0464)$ and bradiarrythmias $(P=0,0157)$, and significantly lower ones in subjects with hypertensive heart disease $(P=0,0367)$. These antibody levels showed no correlation with clinical or paraclinical variables indicative of the degree of cardiac compromise. Our results support the notion that antibodies against sulfatide may play a role in the pathogenesis of Chagas' cardiomyopathy and other forms of heart disease and should be further studied in an effort to determine their potential role in these processes. 